\title{
Effect of Training on Employees' Performance in the Case of Public Sectors of Assosa Zone
}

\author{
Zelalem Oljira $^{1} \quad$ Gudata Abara ${ }^{2}$ \\ 1.Lecturer, Department of Management, College of Business and Economics, Wollega University, Ethiopia \\ 2.Assistant Professor, Department of Accounting and Finance, College of Business and Economics, Wollega \\ University, Ethiopia
}

\begin{abstract}
The main focus of this study is to examine how training influences the employees' performance. The study achieved the objective of the research through survey study with sample organization which have been selected from the five public sectors with help questionnaires for employees and interviews with human resources managers of the sample organizations. Irrespective of number of employees, over $90 \%$ of the sectors were using subjective methods to evaluate employees performance from training and only less than $(10 \%)$ of them was used Kirkpatrick Model. The main conclusion drawn was the emphasis given for training by majority of the firm is still low. Therefore, Organization should allocate sufficient amount of budget to train this key resources of the organization and they should use objective models in addition to the subjective methods, and the organizations should design their training program based the need assessment result to be to increase employees' performance from the training. Keywords: Training, Effect, Employees, Public sectors

DOI: $10.7176 / \mathrm{EJBM} / 11-31-04$
\end{abstract}

Publication date: November $30^{\text {th }} 2019$

\section{INTRODUCTION}

The most valued asset of the organization is human capital (Worku, 2012). Evaluating the importance of training and its effect on performance of public sectors is essential; unless human capital well performs, the public sector cannot achieve their objective. Thus, training in connection with employee's performance has prior concern to capacitate employees and provide better service for the public. This requires understanding of the relationship between training and employees performance in public sector. Every organization strives to be the strongest company in its industry. This competitive edge is dependent upon the availability of resources and their most effective usage. Organization assets may fall in various categories, like physical, financial and human resources. Human resource is considered to be the most vital and useful asset, as other assets can be exploited with the proper use of human resources (Ahmed, et al, 2010). Therefore, in this complex and dynamic environment that greatly influences the service provision of public sectors is performance or ability of employees. Leaders need to have well understanding on the effect of training on employees' performance and to enhance and manage the performance of the employees which will enable the sector to adapt the changing environment and provide better service for the public. Hence the performance of employees in the public sector is also dependent up on the training employees take. With current fast changing technology and working environment the public sector employees needs for learning are increasing to adapt the changing environment and to satisfy their customers need. To enhance the performance of employees in public sector, the public sector leaders plan to improve the skills and knowledge of their employees through training but most public sector leaders do not give due attention to employees knowledge. Organizations are facing increased competition due to globalization, changes in technology, political and economic environments Evans and Barsoux (2002) as cited on Aidah, (2003). Therefore, preparing different training program to employee by public sectors was one way of preparing employee to adjust with changing environment and improving employee's performance.

\section{RESEARCH METHODOLOGY}

The research design was explanatory design as it focuses on the influences of independent variables on dependent variable. This study was designed to establish the relationship between training and employee performance. The data was collected using questionnaires.

Sampling is a method of selecting sample to be included in the study. To conduct the study thoroughly both probabilistic and non-probabilistic sampling techniques were used. Probability sampling was used to minimize biases and to ensure representativeness of the study. While non-probabilistic purposive sampling was another important method of selecting sample that aims in obtaining detailed information to increase the validity of the study. The researchers made five strata of purposively selected sectors on the bases of the organizational differences and nature of work with in which the respondents are working. Simple random sampling was used to select the respondents from stratum. Therefore, stratified followed by simple random sampling techniques was implemented. The target population for this study comprised of leaders, process owners and other employees in the five Assosa zone public sectors. 
The sampling frame of this study will be the list of 25 employees of Education office, 30 employees from agricultural office, 57 employees of Finance and economic development office 53 employees of Water and Mineral office 53 and 57 employees of Civil service and good governance office 57 which is totally 222 respondents were taken from total population. The sample frame of 222 employees were grouped in to five list of categories based on their respective sectors offices to make easier for the selection of the required sample and distribute the selected sample proportionally to the sectors. To determine sample size from the total population, the researchers used the standard table. According to the table if the population 222 and the confidence level is $95 \%$ and margin of error is $5 \%$ the appropriate sample size would be 124. According to Civil Service and good governance Office of Assosa zone (2018), the total number of government employees in those selected five sectors is 222. From these 222 government employees, the sample size is 124 .

Accordingly, 124 sample respondents from the employees' strata were extracted by simple random sampling technique. The distribution of samples to the strata sector was done by proportional method. Firstly; the total sample size determined was divided by proportionally sharing method of proportional allocation under which the sizes of the samples from the different strata are kept proportional to the sizes of the strata. That is, if Pi represents the proportion of population included in stratum $\mathrm{i}$, and $\mathrm{n}$ represents the total sample size, the number of elements selected from stratum $\mathrm{i}$ is $\mathrm{n}$. Pi. To illustrate it, we want a sample of size $\mathrm{n}=124$ to be drawn from a population of size $\mathrm{N}=222$ which is divided into five strata of size $\mathrm{N}_{1}=25, \mathrm{~N}_{2}=30, \mathrm{~N}_{3}=57, \mathrm{~N} 4=57$ and N5 $=53$

Thus, using proportional allocation, the sample sizes for different strata are 17, 14, 32, 32 and 30 respectively which is in proportion to the sizes of the strata with 25:30:57:57 and 53. Proportional allocation is considered most efficient and an optimal design when the cost of selecting an item is equal for each stratum, there is no difference in within-stratum variances, and the purpose of sampling happens to be to estimate the population value of some characteristic.

Table 1. Distribution of sample size to population by proportional technique:

\begin{tabular}{llll}
\hline & & \multicolumn{2}{c}{ Target population \& sample distribution } \\
No & Categories & Number of respondents & Sample size \\
\hline 1 & Agricultural Development office & 30 & 17 \\
2 & Educational office & 25 & 14 \\
3 & Civil service and good governance & 57 & 32 \\
4 & Finance and Economic Development office & 57 & 30 \\
6 & Water, Mineral and energy office & 53 & 20 \\
\hline & Total & $\mathbf{2 2 2}$ & $\mathbf{1 1 3}$ \\
\hline
\end{tabular}

Source: (Report from each office, 2019)

After purposively selecting sectors and calculates the number of sample size using standard table and determines sample size will be 113 .

The researchers need to consider the sources on which to base and confirm the research findings the researchers have two sources, primary and secondary sources. Primary source provides first hand evidence about an event, object, person and work of art. Primary source of data that the researchers used is questionnaires to collect primary data. Secondary sources of data was collected and organized for other purpose and already exists and used to discuss, evaluate and analyze, summarize and process primary sources.

Descriptive statistics frequency and percentage, mean, standard deviation, histogram, and range were used to present socio-economic factors, independent variables and for the level of patient satisfaction. Unlike descriptive statistics, which are used to describe the characteristics (i.e. distribution, central tendency, and dispersion of a single variable, inferential statistics are used to make inferences about the larger population based on the sample. Since a sample is a small subset of the larger population, the inferences are necessarily error prone. That is, we cannot say with $100 \%$ confident that the characteristics of the sample accurately reflect the characteristics of the larger population too. Hence, only qualified inferences can be made, within a degree of certainty, which is often expressed in terms of probability.

Ordinary least squares (OLS) model that shows the relationship between a dependent variable and the independent variables will be used. The value of a dependent variable is defined as a linear combination of the independent variables plus an error term,

$\mathbf{Y}=\boldsymbol{\beta 0}+\boldsymbol{\beta}_{1} \mathbf{X}_{1}+\boldsymbol{\beta}_{2} \mathbf{X}_{2}+\mathbf{E}$,

Where Y-dependent variable- performance

$\mathrm{X} 1$ - Independent variable-training design

$\mathrm{X} 2$ - Independent variable-Training.

E- error term

$\beta$ s are the regression coefficients.

BS are the coefficients associated with each independent variable which measures the change in the mean value of $Y$, per unit change in their respective independent variables. Accordingly, this statistical technique was used to explain the following relationships. Regress performance (as dependent variable) on the selected linear 
combination of the independent variables.

\section{RESULT ANALYSIS AND INTERPRETATION}

The primary focus of this study was to examine how much organizations are effective from employees' training, based on the data which was obtained from sample public sectors through different instruments for data collection; such as questionnaire, semi-structured interview, and review of secondary data by the researchers. And the data were described, analyzed and synthesized in tables, percentage and frequency distribution. Data for the analysis was collected from five (5) public sectors. One hundred twenty four (124) questionnaires were distributed for employees and supervisors (line managers) out of which eighty four (84) questionnaires were returned, and the researchers found it suitable for further analysis. Meaning 74.33 percent response rate was recorded. And these data were supplemented with the data which was obtained through interview with ten (10) human resource managers and review documents of the sample organizations regarding the training budget that allocated by them for training. One hundred thirteen (113) questionnaires were distributed for employees and supervisors (line managers) out of which eighty four (84) questionnaires were returned, and the researchers found it suitable for further analysis. Meaning 74.33 percent response rate was recorded. And these data were supplemented with the data which was obtained through interview with ten (10) human resource managers.

\subsection{Respondents Background}

Table 1 Sex and Age Distribution of the Respondents

\begin{tabular}{|c|c|c|c|c|c|}
\hline Respondents & Sex & Age c & the resp & & \\
\hline & & $18-25$ & $26-35$ & $\geq 36$ & Total \\
\hline Employee & M & 10 & 18 & 9 & 37 \\
\hline & $\mathrm{F}$ & 7 & 7 & 2 & 16 \\
\hline Supervisor & M & 3 & 14 & 12 & 29 \\
\hline & $\mathrm{F}$ & 0 & 2 & 0 & 2 \\
\hline & Total & 20 & 41 & 23 & 84 \\
\hline
\end{tabular}

Source: Survey data, 2019

As the table above depicts only $18(21.43 \%)$ of the respondents were female and the remaining 66(77.2\%) of the respondents were male. Especially the numbers of female respondents were very low at supervisory level, it was $2(6.45 \%)$ of the total respondents from supervisors. The remaining $29(93.55 \%)$ of the respondents were male supervisors. Regarding the age composition of the respondents, the largest group the respondents $41(48.81 \%)$ were at the age of between 26-36 years age group. The second largest group 23(27.38\%) indicated their age as 36 and greater than 36 years old. But the remaining 20 (23.81\%) of the respondents were in the 18-25 age group.

Description and analysis of data which obtained from employees

Table 2. Position of the Respondent in the selected Public sectors

\begin{tabular}{lcccc}
\hline Position & Frequency & Percen & Valid Percen & Cumulative Percen \\
\hline Process Owner & 5 & 20.0 & 20.0 & 20.0 \\
Higher Experts & 1 & 4.0 & 4.0 & 24.0 \\
Experts & 3 & 12.0 & 12.0 & 36.0 \\
Supportive staffs & 16 & 64.0 & 64.0 & 100.0 \\
\hline Total & $\mathbf{2 5}$ & $\mathbf{1 0 0 . 0}$ & $\mathbf{1 0 0 . 0}$ & \\
\hline
\end{tabular}

Source: Survey data, 2019

The sample respondents' position in the respective organization, as the above table illustrates 5(20\%), 1(4\%), $3(12 \%)$ of the respondents were from process owner, higher experts, experts, respectively. Whereas $15(60 \%)$ respondents were from supportive staffs.

Table 3. Methods used by organizations

\begin{tabular}{lllll}
\hline Methods & Frequency & Percent & Valid percent & Cumulative percent \\
\hline Seminar & 3 & 5.7 & 5.7 & 5.7 \\
On-the-job & 23 & 43.4 & 43.4 & 49.1 \\
Understudy & 2 & 3.85 & 3.85 & 52.95 \\
Formal lectures & 11 & 20.8 & 20.8 & 73.75 \\
Other (Vestibule, Apprenticeship....) & 14 & 26.25 & 26.25 & 100.0 \\
\hline Total & $\mathbf{5 3}$ & $\mathbf{1 0 0 . 0}$ & $\mathbf{1 0 0 . 0}$ &
\end{tabular}

Source: Survey data, 2019

As the above table 3 showed that organizations were used different methods of training to train the employee as $43.4 \%, 20.8 \%, 5.7 \%$ of the respondent responded that they have taken the training on-the-job, Formal lectures, seminar respectively. While the rest of the $26.25 \%$ respondents were trained with, understudy training, vestibule, 
apprenticeship and mixture of two or more methods that are mentioned above or other methods. In fact there is no one method which is always effective or best over the others in all condition or time, since training is a situational process that is why no single method is right for every situation.

Table 4. No of times employees have had training since they have joined the organization

\begin{tabular}{ccccc}
\hline No of times & Frequency & Percent & Valid Percent & Cumulative Percent \\
\hline $1-3$ & 44 & 83.0 & 83.0 & 83.0 \\
$4-6$ & 7 & 13.2 & 13.2 & 96.2 \\
$7-9$ & 2 & 3.8 & 3.8 & 100.0 \\
\hline Total & $\mathbf{5 3}$ & $\mathbf{1 0 0 . 0}$ & $\mathbf{1 0 0 . 0}$ & \\
\hline
\end{tabular}

Source: Survey data, 2019

As the table shows $44(83 \%), 7(13.2 \%)$, and 2(3.8\%) of the respondents have taken training from 1 to 3,4 to 6 and 7 to 9 times respectively, since they have been joined in the organizations.

Table 5. Duration of a particular training in the sample organizations

\begin{tabular}{|c|c|c|c|c|}
\hline Period of Training & Frequency & Percent & Valid Percent & Cumulative Percent \\
\hline Less than a month & 14 & 26.4 & 26.4 & 26.4 \\
\hline $1-3$ months & 31 & 58.5 & 58.5 & 84.9 \\
\hline 3-6 months & 6 & 11.3 & 11.3 & 96.2 \\
\hline 7-9 months & 2 & 3.8 & 3.8 & 100.0 \\
\hline Total & 53 & 100.0 & 100.0 & \\
\hline
\end{tabular}

Source: Survey data, 2019

As the above table describes $31(58.5 \%), 6(11.3 \%)$ and $2(3.8 \%)$ of the respondents were responded that they have taken the training for 1-3 months, 3-6 months, 7-9 months, respectively. While the remaining $14(26.4 \%)$, of the respondent were responded that the span of the training that they have taken was less than a month (it may be a week, 2 weeks, 3 weeks or even 2 or 3 days).

Table 6. Content of the Training that Offered by public sectors s for their Employees

\section{Types of Training}

Computer skill

Computer operational, accounting, new

employee orientation, conducting

performance appraisal and other.

Computer, tem building,

\section{managerial/leadership Skill}

Others

Operational

operational, accounting, new employee

orientation ,tem building\&

,managerial/leadership skill

Operational \& new employee orientation

Operational, new employee orientation, tem

building, managerial/leadership skill

Operational \& managerial/leadership skill

Accounting

managerial/leadership skill

\begin{tabular}{|c|c|c|c|}
\hline Frequency & Percent & Valid Percent & $\begin{array}{c}\text { Cumulative } \\
\text { Percent }\end{array}$ \\
\hline 3 & 12.0 & 12.0 & 12.0 \\
\hline 1 & 4.0 & 4.0 & 16.0 \\
\hline 1 & 4.0 & 4.0 & 20.0 \\
\hline 7 & 28.0 & 28.0 & 48.0 \\
\hline 3 & 12.0 & 12.0 & 60.0 \\
\hline 1 & 4.0 & 4.0 & 64.0 \\
\hline 1 & 4.0 & 4.0 & 68.0 \\
\hline 1 & 4.0 & 4.0 & 72.0 \\
\hline 1 & 4.0 & 4.0 & 76.0 \\
\hline 4 & 16.0 & 16.0 & 92.0 \\
\hline 2 & 8.0 & 8.0 & 100.0 \\
\hline 25 & 100.0 & 100.0 & \\
\hline
\end{tabular}

Source: Survey data, 2019

As the above table depicts the employees in the selected public sectors have taken different types of training. As 4(16\%), 3(12\%), 3(12\%), of the respondents replied that they have taken accounting, operational and computer skill training, respectively. And $60 \%$ of the respondent responded that they have taken different types of training or a combination of two or more for example operational, accounting, Change Management, Customer service/ customer handling, managerial/leadership skill, etc.

Evaluation of organizational activities for training and its effectiveness from it from employees' point of view

Evaluation of the general aspects of training and organizational effectiveness from it, in accordance with a fivepoint scale ranging from Never (1), Rarely (2), Sometimes (3), Often (4) to Always (5) by employees of the organization based on the following question. 
Table 7. Evaluation of training aspects and its effectiveness in the organization by the employees

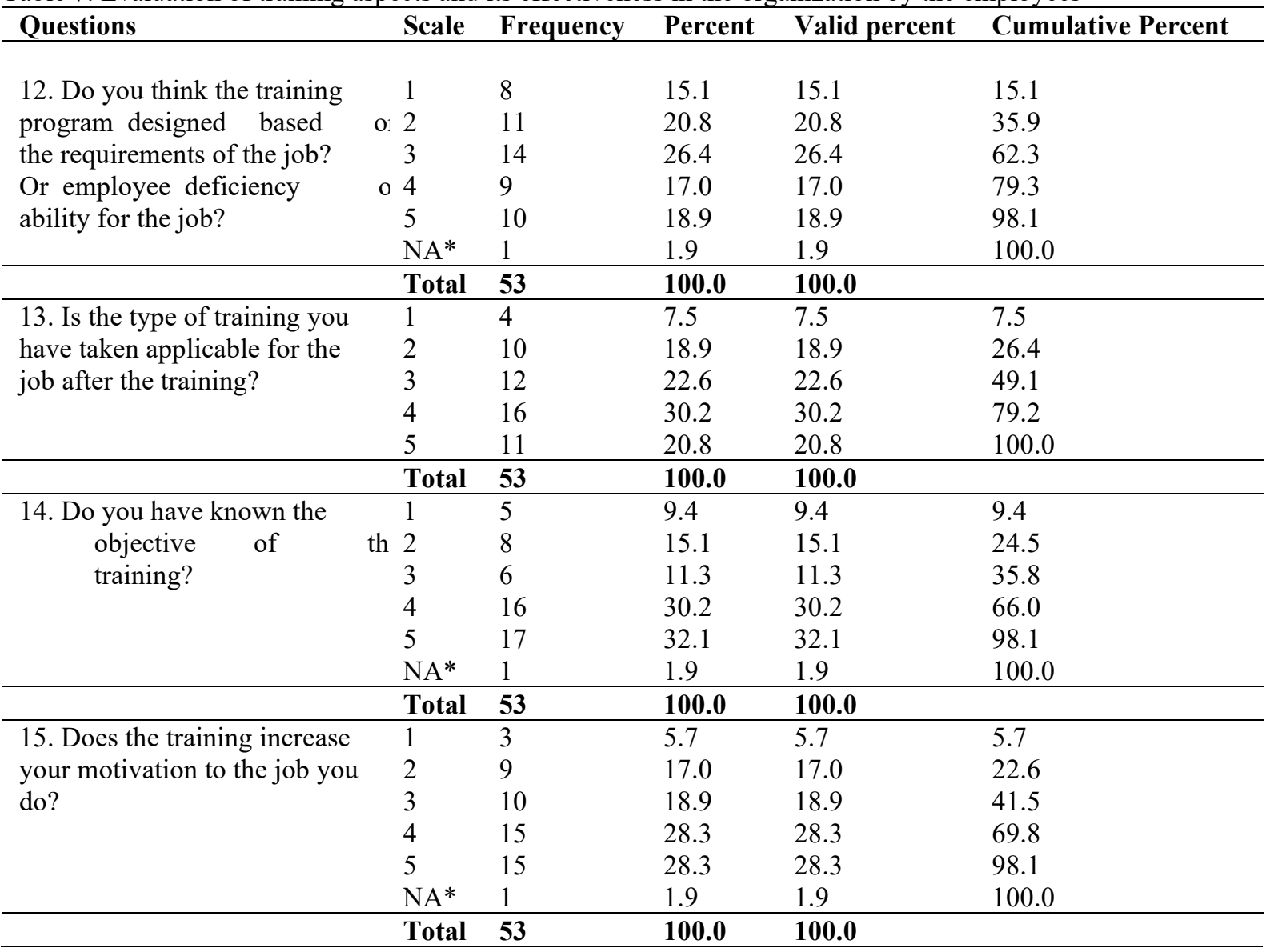

\section{*NA means not applicable}

\section{Source: Survey data, 2019}

Based on the feedback obtained through appraisal the training program should be designed accordingly. Within this fact the researchers asked the employees of the sample organizations to rank how training program designed by their organizations and 14(26.4\%), 11(20.8\%), 10(18.9\%), 9(17\%), and 8(15\%) of the respondent replied that sometimes, rarely, very high, high, and never the training program in the organization was design based on the requirements of the job and employee deficiency of ability for the job, respectively. While1 (1.9) of the respondent said not applicable. As the responses showed that the organizations were not in a position to design the training programs based on the requirements of the job or employee deficiency of ability for the job. If training is not linked to that which an organization uses, does, and delivers, the investment is better made elsewhere (Kaufman, 1985). The respondents were asked to rank the applicability of the training that they have taken at the end of a program in accordance with a five point scale ranging from never (1) to always (5) based on this as the above table portrays $16(30.2 \%), 12(22.6 \%), 11(20.8 \%), 10(18.9 \%)$, and $4(7.5 \%)$ ranked as often, sometimes, always and rarely applicable for the job after the training program respectively. In this respect as more than $73 \%$ of the respondent responded that the training that the employees attended was sometimes and more than that applicable. To coordinate the overall efforts of the training participants for the effectiveness of the organization, everybody in the training should know the objective of the training. Within this fact, the researchers was asked the respondents whether they had known the objective of the training, and 17(32.1\%), 16(30.2\%), 8(15.1\%), 6(11.3\%), and $5(9.4 \%)$ of the respondents responded that always, often, rarely and sometimes and never they know the objective of the training, respectively. While, one of the respondent said that it was no applicable. Even if, some of the respondents responded that they didn't know the objective of the training, more than a half of the respondents were know the objective always and often. Training plays important role towards increasing the employees' motivation in the organization. As respondents from sample organizations responded that $15(28.3 \%), 15(28.3 \%)$, $10(18.9 \%), 9(17 \%)$, and 3(5.5\%) training always, often, sometimes rarely, and never respectively increase their motivation for the job that they have doing. And as the rest $1(1.9 \%)$ of the respondent responded that it was not applicable. As the majority of the respondent proof that the training program can increases the employees' motivation to the job they do. In this aspect the organizations are effective even if the response of some was never. 


\begin{tabular}{|c|c|c|c|c|c|}
\hline Questions & Scale & Frequency & Percent & Valid Percent & $\begin{array}{l}\text { Cumulative } \\
\text { percent }\end{array}$ \\
\hline \multirow{6}{*}{$\begin{array}{l}\text { 16. Does training improves } \\
\text { your skills, knowledge, } \\
\text { attitude change, ner } \\
\text { capability }\end{array}$} & 1 & 3 & 5.7 & 5.7 & 5.7 \\
\hline & 2 & 9 & 17.0 & 17.0 & 22.6 \\
\hline & 3 & 9 & 17.0 & 17.0 & 39.6 \\
\hline & 4 & 16 & 30.2 & 30.2 & 69.8 \\
\hline & 5 & 16 & 30.2 & 30.2 & 100.0 \\
\hline & Total & 53 & 100.0 & \multicolumn{2}{|l|}{$\mathbf{1 0 0 . 0}$} \\
\hline 17. Does the training lea & 1 & 2 & 3.8 & 3.8 & 3.8 \\
\hline you to be satisfied wit & 2 & 12 & 22.6 & 22.6 & 26.4 \\
\hline \multirow[t]{5}{*}{ your job? } & 3 & 16 & 30.2 & 30.2 & 56.6 \\
\hline & 4 & 10 & 18.9 & 18.9 & 75.5 \\
\hline & 5 & 11 & 20.8 & 20.8 & 96.2 \\
\hline & NA* & 2 & 3.8 & 3.8 & 100.0 \\
\hline & Total & 53 & 100.0 & 100.0 & \\
\hline 18. Do you think the metho & 1 & 2 & 3.8 & 3.8 & 3.8 \\
\hline of training used by th & 2 & 9 & 17.0 & 17.0 & 20.8 \\
\hline organization is effective & 3 & 18 & 34.0 & 34.0 & 54.7 \\
\hline & 4 & 14 & 26.4 & 26.4 & 81.1 \\
\hline & 5 & 8 & 15.1 & 15.1 & 96.2 \\
\hline & $\mathrm{N}^{*}$ & 2 & 3.8 & 3.8 & 100.0 \\
\hline & Total & 53 & 100.0 & 100.0 & \\
\hline 19. Do you have enoug & 1 & 6 & 11.3 & 11.3 & 11.3 \\
\hline training that enable & 2 & 14 & 26.4 & 26.4 & 37.7 \\
\hline you to do your job a & 3 & 8 & 15.1 & 15.1 & 52.8 \\
\hline & 4 & 16 & 30.2 & 30.2 & 83.0 \\
\hline \multicolumn{5}{|l|}{ required? } & 9.8 .1 \\
\hline & $\begin{array}{l}5 \\
\mathrm{~N}^{*}\end{array}$ & 1 & 1.9 & 1.9 & 100.0 \\
\hline & Total & 53 & 100.0 & 100.0 & \\
\hline 20. Are you & 7 & & & 13.2 & 13.2 \\
\hline with the overal 2 & 1 & & & 32.1 & 45.3 \\
\hline aspect of th 3 & 7 & & & 13.1 & 58.5 \\
\hline training programs in 4 & 1 & & & 26.4 & 84.9 \\
\hline 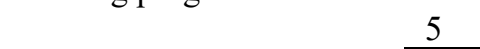 & 8 & & & 15.1 & 100.0 \\
\hline
\end{tabular}

\section{$N A *$ means not applicable $N *$ don't know}

Source: Survey data, 2019

The researchers asked question the employees of sample organizations to rank the position of the organizational training programs by using the given scale how much the it improves their skills, knowledge, attitude and new capabilities and 16(30.2\%), 16(30.2\%), 9(17\%), 9(17\%), and 3(5.7\%) of them responded that always, often, sometimes, rarely and never, respectively the training was improves their skills, knowledge, attitude and new capabilities. From the above response we can understand the organizations were effective from the training since majority of the respondents agreed that the training enables them to improve their skills, knowledge, attitude, and new capability.

The training that offered by the organization should create satisfaction in the mind of the employees in their job that they have doing. As the above table depicts that 16(30.2), 12(22.6\%), 11(20.8), 10(18.9\%), and 2(3.8\%) of the respondents answered that sometimes, rarely, always, often and never the training lead employees' job satisfaction, respectively. Whilst the remaining 2(3.8\%) said that not applicable. As the above figure shows us the organization should do more on the employees' training in respective of employees' satisfaction.

The researchers asked the respondent what they think about the effectiveness of the method employed by the organization and $18(34 \%), 14(26.4 \%), 9(17 \%), 8(15 \%)$, and $2(3.8 \%)$ of the respondents replicated that sometimes, often, rarely, always, never effective, respectively. Whilst, 2(3.8\%) replied they didn't know. As respondent replied that the method these employed by the organizations were effective. But considerable percent of respondents were not agreed with it therefore the organizations should give due attention for the method of training to be effective.

If the organization wants to be competent; it should give enough training for its employees. The above table 
depicts the view of employees in their respective organization about the training they got, and $16(30.2 \%)$, $14(26.4 \%), 8(15.1 \%), 8(15.1 \%)$, and $6(11.3 \%)$ of the respondents responded often, rarely, always, sometimes, and never, respectively, the training that offered by the organization was enough. But only 1(1.9\%) said did not knows. More than a half of the respondents responded that the training offered by the organization often, always and sometimes enough. But more than $30 \%$ percent of the respondents believe rarely and never enough therefore, the position of the organization in this aspect the organizations were not often offered training for their employees. And the respondents also specified the rank of their level of satisfaction from the overall training aspects of the training program $17(32.1 \%), 14(26.4 \%), 8(15.1 \%), 7(13.1 \%)$, and $7(13.2 \%)$ of the respondents were rarely, often, always, sometimes, and never, respectively satisfied with training that offered by the organization since they have joined the organization. But, as $45 \%$ of the respondents responded we can judge the organizations' employees were not satisfied from the employees' training that offered by their respective organizations as employees replied. Therefore, the organization to be effective from the training they should design the over all aspects of the training by keeping in view the interest of the employees.

Description \& analysis of data obtained from supervisors

The supervisors/line managers were asked to rank the position of the organizational effectiveness in accordance with a five- point scale range from very $\operatorname{low}(1), \operatorname{low}(2)$, moderate (3), high (4), and to very high (5) based on the following aspects of training.

Table 9. Evaluation of organizational effectiveness by supervisor

\begin{tabular}{|c|c|c|c|c|c|}
\hline Aspects of Training & Scale & Frequency & Percent & Valid Percent & Cumulative Percent \\
\hline 7.Increased & Low & 2 & 6.5 & 6.5 & 6.5 \\
\hline \multirow{4}{*}{ Productivity } & Moderate & 10 & 32.3 & 32.3 & 38.7 \\
\hline & High & 18 & 58.1 & 58.1 & 96.8 \\
\hline & Vey high & 1 & 3.2 & 3.2 & 100.0 \\
\hline & Total & 31 & 100.0 & 100.0 & \\
\hline \multirow{6}{*}{$\begin{array}{l}\text { 8. Enhanced qualit } \\
\text { of product } \\
\text { service }\end{array}$} & Low & 2 & 3.2 & 3.2 & 3.2 \\
\hline & Moderate & 10 & 32.3 & 32.3 & 35.5 \\
\hline & High & 17 & 54.8 & 54.3 & 89.8 \\
\hline & Very high & 2 & 6.5 & 6.5 & 96.3 \\
\hline & $\mathrm{NA}^{*}$ & 1 & 3.2 & 3.2 & 100.0 \\
\hline & Total & 31 & 100.0 & 100.0 & \\
\hline \multirow[t]{6}{*}{ 9. Improve quantity } & Low & 4 & 12.9 & 12.9 & 12.9 \\
\hline & Moderate & 11 & 35.5 & 35.5 & 48.4 \\
\hline & High & 11 & 35.5 & 35.5 & 83.9 \\
\hline & Very high & 2 & 6.5 & 6.5 & 90.4 \\
\hline & $\mathrm{NA}^{*}$ & 3 & 9.5 & 9.5 & 100.0 \\
\hline & Total & 31 & 100.0 & 100.0 & \\
\hline \multirow{5}{*}{$\begin{array}{l}\text { 10. Improves skills } \\
\text { knowledge, } \\
\text { attitude chang } € \\
\text { new capability }\end{array}$} & Low & 2 & 6.5 & 6.5 & 6.5 \\
\hline & Moderate & 6 & 19.4 & 19.4 & 25.9 \\
\hline & High & 20 & 64.5 & 64.5 & 90.4 \\
\hline & Very high & 3 & 9.7 & 9.7 & 100.0 \\
\hline & Total & 31 & 100.0 & 100.0 & \\
\hline \multirow{6}{*}{$\begin{array}{l}\text { 11. Enhance the us } \\
\text { of tools an } \\
\text { machine, } \\
\text { operational safety }\end{array}$} & Low & 2 & 6.5 & 6.5 & 6.5 \\
\hline & Moderate & 5 & 16.5 & 16.5 & 23.0 \\
\hline & High & 18 & 58.1 & 58.1 & 58.1 \\
\hline & Very high & 1 & 3.2 & 3.2 & 84.3 \\
\hline & $\mathrm{NA}^{*}$ & 5 & 16.1 & 16.1 & 100.0 \\
\hline & Total & 31 & 100.0 & 100.0 & \\
\hline \multirow{5}{*}{$\begin{array}{l}\text { 12. Reduces } \\
\text { accidents }\end{array}$} & Low & 2 & 6.5 & 6.5 & 6.5 \\
\hline & Moderate & 5 & 16.5 & 16.5 & 23 \\
\hline & High & 17 & 54.8 & 54.8 & 77.8 \\
\hline & NA* & 7 & 22.6 & 22.6 & 100.0 \\
\hline & Total & 31 & 100.0 & 100.0 & \\
\hline \multirow{6}{*}{$\begin{array}{l}\text { 13. Reduce lateness, } \\
\text { absenteeism }\end{array}$} & Very low & 2 & 6.5 & 6.5 & 6.5 \\
\hline & Low & 3 & 9.7 & 9.7 & 16.2 \\
\hline & Moderate & 14 & 45.2 & 45.2 & 61.4 \\
\hline & High & 7 & 22.6 & 22.6 & 84 \\
\hline & NA* & 5 & 16.1 & 16.1 & 100.0 \\
\hline & Total & 31 & 100.0 & 100.0 & \\
\hline
\end{tabular}




\begin{tabular}{|c|c|c|c|c|c|}
\hline Aspects of Training & Scale & Frequency & Percent & Valid Percent & Cumulative Percent \\
\hline 14. Eliminates & Low & 1 & 3.2 & 3.2 & 3.2 \\
\hline \multirow[t]{4}{*}{ obsolesce in skills, } & Moderate & 12 & 38.7 & 38.7 & 41.9 \\
\hline & High & 14 & 45.2 & 45.2 & 87.1 \\
\hline & $\mathrm{NA}^{*}$ & 4 & 12.9 & 12.9 & 100.0 \\
\hline & Total & 31 & 100.0 & 100.0 & \\
\hline 15. Reduction in & Low & 1 & 3.2 & 3.2 & 3.2 \\
\hline \multirow[t]{4}{*}{ Errors } & Moderate & 12 & 38.7 & 38.7 & 41.9 \\
\hline & High & 16 & 51.6 & 51.6 & 93.5 \\
\hline & NA & 2 & 6.5 & 6.5 & 100.0 \\
\hline & Total & 31 & 100.0 & 100.0 & \\
\hline 16. Less supervision & Very low & 1 & 3.2 & 3.2 & 3.2 \\
\hline \multirow[t]{5}{*}{ Necessary } & Lo $\mathrm{w}$ & 2 & 6.5 & 6.5 & 9.7 \\
\hline & Moderate & 16 & 51.6 & 51.6 & 61.3 \\
\hline & High & 8 & 25.8 & 25.8 & 87.1 \\
\hline & NA* & 4 & 12.9 & 12.9 & 100.0 \\
\hline & Total & 31 & 100.0 & 100.0 & \\
\hline 17. Reduction in & Very low & 3 & 9.7 & 9.7 & 9.7 \\
\hline \multirow[t]{5}{*}{ Turnover } & Low & 4 & 12.9 & 12.9 & 22.6 \\
\hline & Moderate & 11 & 35.5 & 35.5 & 58.1 \\
\hline & High & 9 & 29.0 & 29.0 & 87.1 \\
\hline & NA* & 4 & 12.9 & 12.9 & 100.0 \\
\hline & Total & 31 & 100.0 & 100.0 & \\
\hline 18. Improved work & Low & 3 & 9.7 & 9.7 & 9.7 \\
\hline \multirow[t]{4}{*}{ Motivation } & Moderate & 6 & 19.4 & 19.4 & 29.1 \\
\hline & High & 18 & 58.1 & 58.1 & 87.2 \\
\hline & NA & 1 & 3.2 & 3.2 & 100.0 \\
\hline & Total & 31 & 100.0 & 100.0 & \\
\hline 19. Decreased & Low & 2 & 6.5 & 6.5 & 6.5 \\
\hline \multirow[t]{5}{*}{ material wastage } & Moderate & 11 & 35.5 & 33.5 & 40.0 \\
\hline & High & 10 & 32.3 & 32.3 & 72.3 \\
\hline & Very high & 3 & 9.7 & 9.7 & 82.0 \\
\hline & $\mathrm{NA}^{*}$ & 5 & 16.1 & 16.1 & 100.0 \\
\hline & Total & 31 & 100.0 & 100.0 & \\
\hline 20. Increased job & Very low & 1 & 3.2 & 3.2 & 3.2 \\
\hline \multirow[t]{4}{*}{ Satisfaction } & Low & 2 & 6.5 & 6.5 & 9.7 \\
\hline & Moderate & 8 & 25.8 & 25.8 & 35.5 \\
\hline & High & 20 & 64.5 & 64.5 & 100.0 \\
\hline & Total & 31 & 100.0 & 100.0 & \\
\hline 21. Increased work & Very low & 1 & 3.2 & 3.2 & 3.2 \\
\hline \multirow[t]{4}{*}{ Efficiency } & Low & 2 & 6.5 & 6.5 & 9.7 \\
\hline & Moderate & 9 & 29.0 & 29.0 & 38.7 \\
\hline & High & 19 & 61.3 & 61.3 & 100.0 \\
\hline & Total & 31 & 100.0 & 100.0 & \\
\hline
\end{tabular}

\section{NA* Not Applicable}

Source: Survey data, 2019

As the above table depicts that $18(58.1 \%), 10(32.3 \%), 2(6.5 \%)$, and the remains $1(3.2 \%)$ of the respondents agreed that the effectiveness of the organization from employees training in relation to increasing productivity of work force was high, moderate, low, and very high. And 17(54.8\%), 10(32.3\%), 2(6.5\%), and 1(3.2\%) of the respondents responded that the return of the training towards enhancing quality of service/product in the organization was high, moderate, very high and low respectively but $1(3.2 \%)$ responded didn't know.

The researchers also asked the participants about how the organization was benefited from the training by improving quantity (for sectors in terms of customer served with a particular period of time) and 11(35.5\%), $11(35.5 \%), 4(12.9 \%), 2(6.5 \%)$ of the respondents responded that high, moderate, low and very high, respectively. Only $3(9.5 \%)$ of the respondent said that it was not applicable. In this case even if majority of the respondents were responded that the organizations were highly and moderately effective from the employees training, some of them indicated that the organization was not effective.

In addition, the majority $20(64.5 \%)$ of the respondents replied that the organization was highly benefited from 
the employees training. And the rest 6(19.4\%), 3(9.7\%), and 2(6.5\%) were responded the return was moderate very high, and low, respectively. In this case, as the respondents proofed that the sample organizations were effective from the training by achieving the intended objective of the training that was improving skills, knowledge, attitude change, and create new capability of the workforce.

The supervisor/ managers invited to evaluate the effectiveness of the organization from the training in relation to the enhancement of the employees' skill, knowledge andlability towards usage of tools and machine, and operational safety in the work place after the training was $18(58.1 \%), 5(16.5 \%), 2(6.5 \%)$, and $1(3.2 \%)$ of the respondents responded that high, moderate, low, and high respectively. But, 5(16.1\%) of the respondents were came back with it is not applicable. As the respondent figure showed that the researchers can conclude organizations were enabling to achieve the objective of the training program which was improve employees' skill, knowledge and ability towards usage of tools and machine, and operational safety in the work place as the participant proofed.

When the respondent asked to evaluate the role of training towards reducing employees accidences in the work place $17(54.8 \%), 5(16.5 \%)$, and $2(6.5 \%)$ of the respondents were responded that high, moderate and low respectively. While, $7(22.6 \%)$ of the said was not applicable. In this case more than $70 \%$ of the respondents were believed that the role of training in reducing accidences in the work place was high and moderate. But $22.6 \%$ of the respondents were said that it was not applicable. Because the probability of accident in the work place is almost zero in the sectors, therefore majority of the respondents from this industry said didn't applicable.

The supervisors/managers were inquired about how they evaluate the return of the training with respect to reducing lateness and absenteeism rate of the employees form the work after the training and 14(45.2\%), 7(22.6\%), $3(9.5 \%)$, and $2(6.5 \%)$ of the respondent responded that moderate, high, low and very low, respectively. But, $5(16.1 \%)$ of them responded that it was not applicable. Even if more than $60 \%$ of the respondents said that the organization was moderately and highly effective, but there considerable number of participant responded agreed that the organization was not effective and didn't applicable. This indicates that the organizations were this much effective from the training through reducing lateness and absenteeism rate of the employees form the work after the training.

The respondents were evaluated the organizational training effort to eliminates obsolesce in skills and came back with high $14(45.2 \%)$, moderate $12(38.7 \%)$, low $1(3.2 \%)$ of the respondents, while $4(12.9 \%)$ of the respondents were replied that not applicable. As $80 \%$ of the respondent replied organizations were high and moderate in achieving the objectives from the training by eliminating obsolesce in skills even if some of the respondent replied as not applicable.

The researchers invited the respondent to rank with the given scale how much the organization was effective from employees training that offered for them to reduce errors made by employees while they are working and they responded that $16(51.6 \%), 4(36.4 \%)$, and 1(3.2\%) of them high, moderate, and low, respectively. But, 2(6.5\%) of the respondent replied that not applicable. Nearly, $90 \%$ of the respondent proofed that organizations were effective from the training by reducing errors commit by the employees while they are working through training.

For the question how the employees training in the organization reduce the extent of supervision of employees by the immediate supervisor after the training and the participants was responded that the training was moderately $16(51.6 \%)$, highly $8(25.8 \%)$, lowly $2(6.5 \%)$, and very lowly $1(3.2 \%)$ reduce the requirement of the supervision. While the rest $4(12.9 \%)$ of the respondent said didn't know. The organizations were moderately and highly effective from the training cost since the requirement of supervision by immediate supervisor is reduce after the training as $75 \%$ of the respondents agreed.

When the respondents examine how the organizational training reduced the turnover rate of the employees after the training program based on the objectives predetermined by the organization they found that $11(35.5 \%)$, $9(29 \%), 4(12.9 \%)$, and 3(9.7\%) moderate, high, low, and very low respectively. Despite the fact that, the rest $4(12.9 \%)$ of them answered it was not applicable. With respect to reducing turnover rate the organizations were not this much effective even $35.5 \%$ and $29 \%$ of the respondents were said moderately and highly, respectively effective because, $22.6 \%$ of the respondents agreed that the effectiveness of the organizations were very low and low.

As the respondent responded the position of organizational training towards improving employees' work motivation was high as $18(58.1 \%)$ of respondents answered, moderate as $6(19.4 \%)$ of the respondent said and low as $3(9.7 \%)$ replied. But $1(3.2 \%)$ of the respondent didn't know. The role of training towards improving employees' work motivation was high in the sample organizations as majority of the answerers replied.

For the question of how do you evaluate the effectiveness of the organization in decreasing material wastage by offering training for its employees, subsequently $11(35.5 \%), 3(32.3 \%), 3(9.7 \%)$, and 2(6.5\%) of the respondent replied that moderate, high, very high, and low, respectively. Whilst, $5(16.5 \%)$ of the respondents retorted that it was not applicable. In respect to reducing material wastage training play an important role in the sample organization. As majority of the respondent proofed that organizations were in a good position to words reducing material wastage in the respective organizations after the training. So, organizations were effective from the 
training.

When the effectiveness of the organization from the employees training with reference to increase job satisfaction by the respondents $20(64.5 \%), 8(25.8 \%), 3(9.5 \%), 2(6.5 \%)$, and $1(3.2 \%)$ of them agreed that training had high, moderate, very high, low, and very low ,respectively contribution in increasing the employees' job satisfaction in the organization after the training. Training is play a prominent role towards increase job satisfaction in the sample organization as more than $90 \%$ of the respondent verified that the sample organization were effective from the training in relation to increasing employees satisfaction.

There is no doubt training can increase work efficiency of the work force. The researchers asked the supervisors of the sample organizations to weigh up how the organization they are working was effective from employees training in relation to increases work efficiency and 19(61.3\%), 9(29\%), 2(6.5\%), and 1(3.2\%) of them agreed that the training was high, moderate, low, and very low, respectively in increasing work efficiency among the worker after the training they were lead/or supervise. Except $9.7 \%$ of the respondents the rest of the respondents agreed that the organization they have working was effective from the training in relation to increase in work efficiency of the work force after the training. So, organizations were effective from the training in relation to improving work efficiency in the work place.

\section{Description and analysis of data obtained through interview}

Under this section the data obtained through interview with the human resource managers (a person who responsible for human resource management activity of the organization) about the training and effectiveness of the organization from for employees' training was described and analyzed below accordingly the order of the questions.

\section{Question 1}

"Did your organization give training for the employees for the last 3 years?"

There is no doubt that training is indispensable for each and every organization, irrespective of their nature, type and industry in which it found. It is an established fact that no seriously minded organization can be staffed by people with expertise and potentials in the various discipline needed for its total functioning simply by recruitment. According to (Alipour et al, 2009) any organization that wants to succeed and to continue to succeed, has to maintain workforce consisting of people who are willing to learn and develop continuously to be successfully. Within this fact the response of all the respondents was 'yes'.

\section{Question 2}

Why your organization gave the training? What types of training? And what methods the organization is used? All of the respondents were responded that the reason why they gave a training for their employees was to upgrade the skills, knowledge, capabilities, and attitude of the employees in the area in which the employees had deficiency, in order to improve the employees' performance in a given task or job that assigned for him/her, to increase productivity, to reduce material wastage, work efficiency, to increase product (quality, quantity, precision (in size, quality)) and to keep safety \& health of the employee and others. By keeping in view the above general objective for all respondents specifically respondents had different reasons these were initiated them to provide training for their employees, in addition to the above general objectives, among them one of the respondents replied that the organization offered training for its employee in order to introduce the workforce with the new technologies.

\section{Question 3}

'How do you express the frequency of training per year for each employee on average and the cost of training allocate for each employee on average per year?'

Within this fact all the respondent replied that the frequency training for each employee per year was determined based on the skill gap which was observed on the employees between the actual skill/knowledge/ability possessed by job incumbent and the job requirement, the nature of the work, complexity of the work, cost per training and other factors were determine employees' training frequency per year in the organizations. Within these variables frequency of training per year per employees varies within this rang from zero to six.

\section{Question 4 and 5}

Do you conduct evaluation of the training effectiveness?

Within this reality the researchers asked the respondent whether the organization conducted evaluation of training effectiveness during and after the program. Therefore, the entire respondents responded that they did evaluation. But, one of the respondent replied that the organization has a standard criterion to conduct evaluation of the effectiveness of the organization from the training. As he said a training program to be evaluated there must be 20 or greater than 20 attendances at a given session unless and until it is not evaluated but there was informal evaluation system at break time and other situation it allowed for it.

How do you evaluate the return and level of performance outcome of the training in terms of the?

a. Objective of the training.

As narrated above the organizations had different objectives these were initiated the organization to provide training for their employees, by keeping in mind these objective of the organization the researchers asked the HR manager/ person who responsible for this activity of the respective organizations how they evaluate the return and level of 
performance outcome of the training with respect to the specific objective of the particular training that was predetermined by the organization to attain after the training of the work force. Based on this, only 2 of the respondent replied that there was an improvement in employees' performance after the training.

\section{Question 6}

Which section of the training is evaluated?

All of the respondent replied any training that offered for any section of the employee evaluated but one of the respondent said that even if each section of the training was evaluated, the training for worker in manufacturing gave due attention to appraise how much these training participants were improved in all aspects (skill, knowledge, safely usage of machine, productivity etc..) in which the training offered, as he said this section not only got highest attention in the valuation aspect, but also in budget for training.

\section{CONCLUSION}

The finding of this survey revealed that the reason which initiated the sample organizations to gave training for their employees with the objective of upgrade the skills, knowledge, capabilities, and attitude of the employees in the area in which the employees had deficiency, in order to improve the employees' performance in a given task or job that assigned for him/her, to increase productivity, to reduce material wastage, work efficiency, to increase product (quality, quantity, precision (in size, quality)) and to keep safety \& health of the employee and others. And to deliver the training the organizations were used different methods but two dominant methods were On-the-Job and Formal lectures.

As the finding revealed that all of the organizations were conducted an evaluation of training effectiveness but there was a response that proofed that not evaluated all training these were offered by the organization rather based on the criteria. Within in this fact, although there are a number of model available for them for evaluation purpose, over $90 \%$ of them were using subjective methods to evaluate organizational effectiveness from employees' training and only less than (10\%) of them was used Kirkpatrick Model, as evaluation tools. Even 10\% them was not used the model always but used it sometimes.

\section{RECOMMENDATIONS}

In light of the findings the researchers forwards the following suggestions for the concerned body:-

- Organization should allocate sufficient amount of budget to train this key resources of the organization. Since investment on people, both in developing and maintaining the appropriate skills, knowledge, and ability are vital part of the organization's strategy for the future and it is a strategic weapon in the battle for competitive advantage.

- Since the organizations are investing considerable amount of resource for employees' training they have to get satisfactory return on investment. Means linking the training function and activities to the company's overall business activity, to do so organizations should use objective models in addition to the subjective methods to improve the accuracy of the result of organizational effectiveness. Other ways a training program is not complete until they have evaluated results with the help of precise method. A key to obtaining consistent success with training programs is to have a systematic approach to measurement and evaluation.

- Any training should be takes place based on proper analysis of its contribution to the effectiveness and efficiency of an organization unless and until the investment on it should invest in another activity. Therefore, organizations should design their training program based on this fact especially leather firms should take a care on this issue.

\section{REFERENCES}

Aldaha, N. 2013. The effect of training on employee's performance. Uganda Business, Economic and Tourism Journal. appril.3-5, 2007.

Ashima,A. Gour.S, 2013. Technique for performance appraisal. International journal of Engineering and advance technology.

Australian human resource institute, 2013. Types of performance appraisal system.

Performance Management information sheet.

Ayesha Tabassum, 2012. Performance appraisal practices in developing country.

Carole Gump rich .2007. Recruiting and Training employees. London Swine conference

Cokins, G.2004. Finding the missing piece Chris obsi Australian journal of business and commitment. British journal of management,7(2); pp 169-197.

Cris Obsi .2011. Employee Training and development in Nigerian organization, some

Elaine D, Pulakos, 2004. Performance management a road map for developing and.Employee and organization . Far East journal of psychology and business.2 (9).

Employee performance .International journal of human resource studies,V.4, No.4 Email.dablew@africau.edu. 
employees performance in courier companies in Darussalam, Tanzania. Evaluation performance Management systems. Society for human resource management

Flacher, C. and Williams, R. 1996. Management, Job satisfaction and organizational

Fred.C.Lunanberg, 2012. Performance appraisal methods and rating errors. International Hand book for measuring employees performance.

Hung, Che $\mathrm{Wu}, 2002$. Evaluation of employees initial orientation and on the job training in the mid and large sized hotels in the twin cities with regard to service training. Research paper.

Idoko,C, Emanuel and Dansum, A. 2011. Employee training and productivity in Nigeria

IPek.K. 2005. General over view of training effectiveness and Measurement models. Implication for national Transformation. International journal of humanities and social science Vol.2.No.22

Journal of Commerce and Tourism education faculty.

Journal of scholarly academic intelligence diversity.Vol.3 No.3

Journal of science, Arts, and Commerce,V.3, 2(2). www.researchers world.com.

khanzeb@ksu.edu.sa

Khawaja, J,and Nadeem A.2012. Training and development program and its benefit to

Khawaja,J. and Nadem,A. 2013. Training and Development program and its benefit to employee and organization .European Journal of business and Management. Vol.5 no. 2

Lattem P. Steel.T and Saari.L, 1982. The effects of participation and goal difficulty on performance, 35(3); PP 677-686.

Lena K. 2013. Analysis of country specific practices, global best practices and employees preference in performance management. Global performance management multinational enterprise.

Malesetty M and Jim lee. Performance management methods in manufacturing industries review and suggestion. Engineering and Technology program.

Management research and closing the intelligence gap.

Measurement. Health resources and service administration, V.3, 2(2) .www.research

Mohammed,I. Hassan, Saira, Y.and Ahmednur .2011. Critical analysis of performance appraisal system for teachers in public sector university of Pakistan. African journal of business management, 5(9), 3735-3744. Http; www.acadamic journals.org.

Nelson, J, Hilary, V and Michael, N. 2012. Relationship between on job training and Observation and agenda for research,pp (82-91). Obsi.chris@yahoo.com Performance. Human resource planning. 26(1); 51-62.

Process and usefull hints for supervisors and staff.

Ramlall.S. 2003. Measuring human resource management effectiveness in improving

Scott Brum , 2007, What impact does training have on employee commitment and employee turnover. Schmidt labor Research center Seminar Research series

University of Missouri, 2008, Performance management tool to employee success. Guidelines

US Department of health and human services.2011. Performance management

US Office of Personnel management, 2011. Performance appraisal assessment tool instructions

Wenham $\mathrm{p}$ and Nelson, J. and Mentline, N. 2014. Relationship between training and.Woreda. Research paper.

Worku Gadisa, 2012. Leadership Style and Employee Motivation: A Case of Lege-Hida

www.iiste.org. 